\title{
An anti-inflammatory diet intervention for knee osteoarthritis: a feasibility study
}

Indiana Cooper ${ }^{1}$, Peter Brukner², Brooke L. Devlin³ ${ }^{3}$ Anjana J. Reddy ${ }^{3}$, Melanie Fulton ${ }^{3}$, Joanne L. Kemp ${ }^{2}$ and Adam G. Culvenor ${ }^{2^{*}}$

\begin{abstract}
Background: Knee osteoarthritis has an inflammatory component that is linked to pain and joint pathology, yet common non-surgical and non-pharmacological interventions (e.g., exercise, calorie restricting diets) do not typically target inflammation. We aimed to evaluate the feasibility of a telehealth delivered anti-inflammatory diet intervention for knee osteoarthritis.
\end{abstract}

Methods: This 9-week single-arm feasibility study recruited participants aged 40-85years with symptomatic knee osteoarthritis (inclusion criteria: average pain $\geq 4 / 10$ or maximal pain $\geq 5 / 10$ during past week). All participants received a telehealth-delivered anti-inflammatory dietary education intervention involving 1:1 consultations at baseline, 3- and 6-week follow-up. The diet emphasised nutrient-dense wholefoods and minimally processed antiinflammatory foods and discouraged processed foods considered to be pro-inflammatory. The primary outcome of feasibility was assessed via: i) eligibility, recruitment and retention rates; ii) self-reported dietary adherence; iii) adverse events; and iv) treatment satisfaction. Post-intervention interviews evaluated the acceptability of the dietary intervention delivered via telehealth. Secondary outcomes included changes in self-reported body mass, Knee injury and Osteoarthritis Outcome Score (KOOS), health-related quality of life (EuroQoL-5D), analgesic use and global rating of change. Worthwhile effects were determined by the minimal detectable change (MDC) for all five KOOS-subscales (pain, symptoms, activities of daily living, sport/recreation, quality of life) being contained within the $95 \%$ confidence interval.

Results: Forty-eight of seventy-three (66\%) individuals screened were eligible and 28 enrolled over 2 months (82\% female, mean age $66 \pm 8$ years, body mass index $30.7 \pm 4.8 \mathrm{~kg} \cdot \mathrm{m}^{-2}$ ). Six participants withdrew prior to final follow-up ( $21 \%$ drop-out). Of those with final follow-up data, attendance at scheduled telehealth consultations was $99 \%$. Selfreported adherence to diet during the 9-week intervention period: everyday $=27 \%$, most of time $=68 \%$ and some of time $=5 \%$. Two minor adverse events were reported. Change scores contained the MDC within the 95\% confidence interval for all five KOOS subscales. Suggestions to improve study design and limit drop-out included an initial faceto-face consultation and more comprehensive habitual dietary intake data collection.

Conclusion: This study supports the feasibility of a full-scale randomised controlled trial to determine the efficacy of a primarily telehealth-delivered anti-inflammatory dietary education intervention in adults with symptomatic knee osteoarthritis.

\footnotetext{
*Correspondence: a.culvenor@latrobe.edu.au

${ }^{2}$ La Trobe Sport and Exercise Medicine Research Centre, School of Allied

Health, Human Services and Sport, La Trobe University, Bundoora, Victoria

3086, Australia

Full list of author information is available at the end of the article
} permits use, sharing, adaptation, distribution and reproduction in any medium or format, as long as you give appropriate credit to the original author(s) and the source, provide a link to the Creative Commons licence, and indicate if changes were made. The images or other third party material in this article are included in the article's Creative Commons licence, unless indicated otherwise in a credit line to the material. If material is not included in the article's Creative Commons licence and your intended use is not permitted by statutory regulation or exceeds the permitted use, you will need to obtain permission directly from the copyright holder. To view a copy of this licence, visit http://creativecommons.org/licenses/by/4.0/. The Creative Commons Public Domain Dedication waiver (http://creativeco mmons.org/publicdomain/zero/1.0/) applies to the data made available in this article, unless otherwise stated in a credit line to the data. 
Trial registration: ACTRN12620000229976 prospectively on 25/2/2020.

Keywords: Osteoarthritis, Knee Joint, Anti-inflammatory diet, Mediterranean diet, Low-carbohydrate diet, Telehealth

\section{Background}

Knee osteoarthritis (OA) is the leading cause of global disability in the elderly and carries a tremendous health and economic burden [1]. In Australia alone, OA-related healthcare costs exceed $\$ 2.1$ billion annually $[2,3]$. With no cure or regulatory approved disease-modifying drugs, treatment for OA is largely symptomatic [4]. Surgical joint replacement is an effective procedure in the right candidate but is limited to those with end-stage joint disease, and up to $20 \%$ of patients have no clinically meaningful improvement $[5,6]$.

Clinical guidelines recommend exercise-therapy and weight-loss as first-line treatments for knee OA that target typical physical impairments (e.g., muscle weakness, excessive joint loads) [7]. Exercise-therapy is supported by more than 50 randomised controlled trials (RCTs), yet its effect on pain and quality of life is only moderate [7, 8]. Weight loss of at least $5-10 \%$ body weight has been shown to improve OA-related symptoms and function [8-11]. However, typical dietary interventions are caloric restrictive, which can hinder compliance and long-term sustainability [12]. A recent meta-analysis highlighted that, within two years, more than half of weight lost was regained, and by 5 years, this figure jumps to over $80 \%$ [13].

Anti-inflammatory diets provide an alternative to caloric restrictive approaches by targeting local and systematic inflammation, both contributors to OA disease onset, progression and symptom burden [14-16]. In recent years, diets high in anti-inflammatory properties have garnered significant interest in the prevention and management of chronic diseases [17]. Typically, these diets are high in unrefined and minimally processed foods, dense in nutrients including fibre, monounsaturated and polyunsaturated fatty acids (MUFAs/PUFAs) and have been shown to significantly reduce inflammation independent of weight loss [17-19]. Consumption of foods rich in polyphenols such as fruits, vegetables, herbs, spices, and olive oil can decrease inflammation via antioxidant and anti-inflammatory properties which neutralise free radicals and other reactive oxygen species [20]. Alternatively, ultra-processed foods with a high glycaemic load, such as refined carbohydrates (breads, grains, starchy vegetables, junk foods), can increase the production of free radicals and proinflammatory cytokines, leading to a pro-inflammatory milieu [21]. Omega-3 fatty acids are also a key nutrient within an anti-inflammatory diet, with nuts, seeds and fish being a rich source for omega-3 fatty acids [22]. Diets rich in omega-3 fatty acids are crucial for achieving a more desirable omega- 6 to omega- 3 ratio in a healthy diet. In contrast omega- 6 fatty acids, can be converted into arachidonic acid, contributing to precursors for proinflammatory eicosanoids [21]. An elevated omega-6:omega-3 ratio mediates vascular damage and reduces anti-inflammatory processes, likely exacerbating oxidative stress, which increases the risk and severity of chronic disease, including OA [23-25].

Small studies (i.e., $<50$ participants) that have included anti-inflammatory diets as an intervention for knee OA provide preliminary indications that they are feasible and effective at reducing symptoms and inflammation associated with knee OA over 12-16weeks [25, 26]. However, these studies relied upon regular and intensive face-to-face consultations. With the recent global pandemic (COVID-19), there have been calls for evaluations of the effectiveness of remotely delivered healthcare (i.e., telehealth), including dietary interventions [27, 28]. It is important to establish the feasibility of a telehealthdelivered anti-inflammatory dietary intervention prior to undertaking a full-scale RCT.

The primary aim of this study was to determine the feasibility of a full-scale RCT to estimate the effectiveness of an anti-inflammatory dietary intervention delivered via telehealth. Our secondary aim was to determine if a worthwhile effect was observed for improvements in selfreported knee symptoms, function, and quality of life.

\section{Methods \\ Study design}

This single-arm feasibility trial was conducted at La Trobe University, Melbourne, Australia. The trial was prospectively registered with the Australian New Zealand Clinical Trial Registry (ACTRN12620000229976) and reporting adheres to the Consolidated Standards of Reporting Trials (CONSORT) statement for pilot and feasibility studies [29]. Ethical approval was gained from La Trobe University Human Ethics Committee (HEC19525) and all participants provided written informed consent prior to enrolment. All methods were carried out in accordance with relevant guideline and regulations. All patient-reported outcomes were completed via an online Research Electronic Data Capture (REDCap) platform.

While we initially planned to randomise participants into one of two groups (anti-inflammatory diet vs 
no-intervention control), and collect biochemical (i.e., serum inflammatory markers), body composition (i.e., Dual energy X-ray absorptiometry (DEXA) scan) and physical performance outcomes (i.e., $30 \mathrm{~m}$ walk test, $20 \mathrm{~s}$ chair stand test), we modified our study protocol prior to the first enrolled participant due to government and university COVID-19 restrictions so that all outcomes were self-reported and completed remotely.

\section{Participant recruitment and eligibility}

We initially aimed to enrol 60 participants ( $n=30$ antiinflammatory diet, $n=30$ control) based on previous feasibility trials evaluating health-professional guided interventions for musculoskeletal conditions [30-32] which was deemed sufficient to assess feasibility parameters. Due to COVID-19, our study was adapted to a single-arm feasibility study, in which we aimed to enrol 30 participants into the anti-inflammatory diet intervention. Between February and April 2020, study information was distributed via an online newsletter to individuals on a registry who had completed an exercise-therapy program for OA throughout Australia (i.e., GLA:D Australia) [33]. Individuals contacted the research team to undergo eligibility screening via phone.

Inclusion criteria were: (i) aged 40 to 85 years; (ii) average knee pain of $\geq 4 / 10$ on a numeric rating scale or maximum intensity of $\geq 5 / 10$ in past 7 days; (iii) ability to understand written and spoken English; (iv) willing to follow a 9-week anti-inflammatory diet. Exclusion criteria were: (i) knee pain not primarily due to OA (e.g., fibromyalgia, tumour, referred pain); (ii) already participating in a specific diet (e.g., low carbohydrate high-fat, Paleo, Mediterranean); (iii) unstable weight ( $>5 \mathrm{~kg}$ weight change in past 3 months).

\section{Anti-inflammatory diet intervention}

The anti-inflammatory diet intervention was administered by Accredited Practising Dietitians (APD) or by researchers who were specifically trained by accredited dietitians. Standardised case report forms were used during each telehealth consultation to maximise standardisation of the dietary intervention.

The dietary intervention was delivered over 9-weeks, with telehealth consultations via Zoom platform (Zoom Video Communications, Inc., San Jose, Ca, North America, Version: 5.0.1) for all baseline consultations, with the option for either Zoom or telephone consultations (based on participant preference) at 3- and 6-weeks (Table 1). Baseline consultations were conducted over $45-90 \mathrm{~min}$ depending on participant understanding of anti-inflammatory diets and completion of food diaries. Follow-up consultations were conducted over 10-15 min. The baseline consultation consisted of education regarding the intervention and answering participant questions. Participants were encouraged to follow a diet containing minimal processed foods and higher amounts of "good" fats and wholefoods. The wholefoods encouraged in moderate amounts were: lean meats, eggs and dairy; and those encouraged in higher amounts were: fish, fruit, vegetables, nuts and seeds. "Good fats" included monounsaturated fats with a favourable omega-6:omega-3 ratio such as fish, seeds and olive oil. Participants were requested to limit highly processed and refined foods such as refined carbohydrates (pasta, bread, rice), confectionary and processed meats. Participants were encouraged to consume a normocaloric diet and to eat to satiety. Information provided via telehealth was supplemented by a study booklet that was mailed to participants detailing all dietary advice and examples of food to consume and

Table 1 Overview of the anti-inflammatory diet intervention ${ }^{a}$

\begin{tabular}{|c|c|}
\hline Name & Anti-inflammatory diet intervention \\
\hline What & Education and discussion 1-to-1 supplemented with a study booklet of examples of foods to consume and recipes \\
\hline Who provides & Accredited Practising Dietitian or researchers (trained by dietitian to deliver the intervention). \\
\hline How & $\begin{array}{l}\text { 1-to-1 telehealth sessions via Zoom or telephone consult (when video teleconferencing was not available for follow-up } \\
\text { appointments). All baseline appointments were delivered by telehealth videoconferencing. }\end{array}$ \\
\hline Where & Remotely conducted telehealth sessions by researchers in Melbourne to participants throughout Australia. \\
\hline When \& how much & $\begin{array}{l}\text { Telehealth 1-to-1 sessions: baseline, 3- and 6-week follow-up. } \\
\text { Baseline: 45-90 min. Follow-ups: 10-15 min. }\end{array}$ \\
\hline Tailoring & $\begin{array}{l}\text { - Dietary education provided including list of acceptable food groups and possible adverse outcomes. } \\
\text { - Standardised meal plan and shopping list provided, however, encouraged acceptable modifications to suit individual } \\
\text { lifestyle and palate. } \\
\text { - Individualised feedback and education provided at each follow-up after assessment of most recent 3-day food diary. } \\
\text { - Individualised education provided at each follow-up for participants who had specific questions regarding their food } \\
\text { intake and acceptable foods. }\end{array}$ \\
\hline How well & $\begin{array}{l}\text { Attendance at telehealth sessions recorded by the intervention dietitian or trained researcher. } \\
\text { Self-reported dietary adherence recorded on a 5-point Likert scale (ranging from never adherent to adherent every day). }\end{array}$ \\
\hline
\end{tabular}

${ }^{\text {a }}$ Described according to the Template for Intervention Description and Replication [34] 
avoid (Additional file 1). Participants were instructed not to partake in any other knee OA intervention during the 9-week study period, other than stable medication doses.

To guide education content, data from a validated multiple pass 24-h food recall (completed at baseline) [35], and a validated 3-day food diary (completed at 3-, 6- and 9-weeks), were used to provide feedback and discuss participant-specific strategies to optimise adherence. The multiple pass 24-h food recall and 3-day food diaries were analysed using FoodWorks10 ${ }^{\circledR}$ (Xyris Software, Brisbane, QLD, Australia) incorporating the AUSNUT 2013, AusBrands 2015 and AusFoods 2015 databases. Participants were given the option of either paper-based recording for the 3-day food diaries, or were taught to use a smartphone-based application, Easy Diet Diary. Easy Diet Diary is a commercial food diary and calorie counter that is developed and owned by Xyris Software, Brisbane, QLD, Australia). Macronutrient, micronutrient and food group analysis was exported from FoodWorks $10^{\circledR}$.

\section{Outcomes}

\section{Baseline characteristics}

Participant characteristics (e.g., age, sex, symptom duration, education, employment, income, physical activity, current diet) were collected at baseline. Symptom duration was answered by the question: "In the most affected knee, what is the duration of your knee pain?". Symptom duration was then split into four categories from 0-6 months to $>3$ years. Baseline diet was assessed with the multiple pass 24-h food recall [35]. The timepoints of all outcome measure collection are presented in Table 2.

\section{Primary outcome: Feasibility}

Feasibility was assessed according to previously published recommendations [36] and included the following parameters: (i) eligibility rate; (ii) recruitment rate; (iii) retention rate; iv) dietary adherence; v) 3-day food diary completion; vi) attendance at telehealth consults and vii) occurrence of adverse events. Proceeding to a full-scale RCT was considered feasible where parameters were comparable to previously published recommendations, or reasonable amendments could be applied to achieve these results in future trials.

Dietary adherence was assessed via a 5-point Likert scale asking how often the dietary intervention was followed (never to every day), which was supplemented by completion of the 3-day food diary at each follow-up to assess specific dietary intake. Adverse events were defined as those resulting in new limitations to normal daily activities, recreational- or work-related activities, or symptoms requiring medical care.

We also assessed acceptability, accessibility, adherence, and treatment satisfaction during semi-structured
Table 2 Overview of data collection

\begin{tabular}{lllll}
\hline Variable & Baseline & Week 3 & Week 6 & Week 9 \\
\hline Ethnicity & $\mathrm{X}$ & & & \\
Highest education level & $\mathrm{X}$ & & & \\
Employment status & $\mathrm{X}$ & & & \\
Civil status & $\mathrm{X}$ & & & \\
Living situation & $\mathrm{X}$ & & & \\
Comorbidities & $\mathrm{X}$ & & & \\
Knee symptom history & $\mathrm{X}$ & & & \\
24-h recall food diary & $\mathrm{X}$ & & & \\
Current knee pain & $\mathrm{X}$ & $\mathrm{X}$ & $\mathrm{X}$ & $\mathrm{X}$ \\
Height and weight & $\mathrm{X}$ & $\mathrm{X}$ & $\mathrm{X}$ & $\mathrm{X}$ \\
EuroQoL-5D & $\mathrm{X}$ & $\mathrm{X}$ & $\mathrm{X}$ & $\mathrm{X}$ \\
Knee injury and Osteoar- & $\mathrm{X}$ & $\mathrm{X}$ & $\mathrm{X}$ & $\mathrm{X}$ \\
thritis Outcome Score & & & & \\
Analgesic medication use & $\mathrm{X}$ & $\mathrm{X}$ & $\mathrm{X}$ & $\mathrm{X}$ \\
3-day food diary & & $\mathrm{X}$ & $\mathrm{X}$ & $\mathrm{X}$ \\
Adverse events & $\mathrm{X}$ & $\mathrm{X}$ & $\mathrm{X}$ & $\mathrm{X}$ \\
\hline
\end{tabular}

interviews following the intervention. Interviews were conducted by a single researcher and recorded via Zoom (Zoom Video Communications, Inc., San Jose, CA, North America, Version: 5.0.1). Responses to 20 openended questions (Additional File 2) covering themes such as: (i) acceptability of dietary intervention; (ii) accessibility of telehealth consultations; (iii) adherence to dietary intervention; (iv) treatment satisfaction; and (iv) comparison to exercise-based interventions. The interviews were transcribed verbatim and explored using thematic analysis [37]. Participant responses were then coded in an inductive manner. Post-analysis, the themes were verified between two investigators (IC, MF).

\section{Secondary outcome: Knee symptoms}

Knee symptoms were assessed using the Knee injury and Osteoarthritis Outcome Score (KOOS) [38]. The KOOS is a 42-item patient-reported outcome measure consisting of five subscales: Pain, Symptoms, Activities of Daily Living (ADL), Function in Sport and Recreation (Sport/ Rec), and Quality of Life (QoL). Participants rate each item on five graded adjectival response options, then mean scores for each subscale are calculated and converted to be expressed as a score ranging from 0 to 100 , with 100 representing no problems. $\mathrm{KOOS}_{4}$, the mean score of four of the five subscales (all except Sport/Rec) will also be assessed as this has been used as a primary outcome in trials of knee OA [39]. KOOS is a valid, reliable, and responsive measure during short-term and long-term follow-up for knee OA [40]. We also assessed self-reported knee pain during the previous 7 days using 
a $100 \mathrm{~mm}$ visual analogue scale (VAS) for both average knee pain and most severe knee pain.

\section{Secondary outcome: health-related quality of life}

Health-related quality of life was assessed with the EuroQol-5D (EQ-5D), which comprises five health domains (mobility, self-care, usual activities, pain and anxiety/ depression) as well as a VAS for overall health status from 0 (worst) to 100 (best) [41]. Responses for the five health domains were combined using established formula to provide an overall health-related quality of life index value [42].

\section{Secondary outcome: analgesic medication}

Change in analgesic medication use from baseline to 9-week follow-up was assessed with a 7-point Likert scale (much less to much more).

\section{Secondary outcome: body mass}

Weight $(\mathrm{kg})$ and height $(\mathrm{cm})$ were self-reported by participants following advice regarding how to accurately assess these, ensuring consistent weighing times and conditions (e.g., before first meal) and BMI $\left(\mathrm{kg} . \mathrm{cm}^{-2}\right)$ was calculated.

\section{Data analysis}

Participants who completed baseline and 9-week followup assessments (primary study endpoint) were included in the analysis, as per CONSORT recommendations [29]. Feasibility outcomes were reported descriptively. Within-group change in secondary continuous outcomes were reported as mean (95\% confidence interval (CI)) change and evaluated with paired t-tests. For nonnormally distributed data, a Wilcoxon Signed Rank test assessed pre-post-intervention differences. Treatment effects were potentially worthwhile if previously estimated minimal detectable change (MDC) scores for each measure were contained within the $95 \% \mathrm{CI}$. We used the macronutrient, micronutrient, and food group analysis data from FoodWorks $10^{\circledR}$ to calculate changes in dietary intake over time. Normally distributed intake data (confirmed with Kolmogorov-Smirnov test) are reported as mean \pm standard deviation (SD) and differences evaluated with paired t-tests. Non-normally distributed intake data are reported as median (interquartile range (IQR)) and change overtime evaluated with Wilcoxon Signed Rank test. Statistical analyses were conducted in Stata (StataCorp, V.16.0) with $\alpha=0.05$.

\section{Results}

\section{Feasibility}

During March and April 2020, 109 individuals responded to the study invitation. Seventy-three $(67 \%)$ individuals were screened, with 48 (64\%) of those meeting eligibility criteria. Of the eligible participants, 28 (58\%) were enrolled. Twenty-two participants completed the entire 9-week dietary intervention and final follow-up assessments, with six withdrawals (drop-out rate $21 \%: n=2$ could not follow intervention, $n=2$ due to personal reasons, $n=1$ due to health reasons and $n=1$ based on GP recommendation) (Fig. 1). The results of each aspect of feasibility are summarised in Table 3 . There were two adverse events reported. One participant developed constipation, which resolved after further dietary advice given at the 3-week follow-up appointment, and a second participant had an injury to the knee following a fall, which the participant reported as unrelated to the diet.

Of the 22 participants with 9-week follow-up data, $6(27 \%)$ reported being adherent every day, 15 (68\%) reported being adherent most of the time and 1 (4.5\%) reported being adherent sometimes. Post-study interviews $(n=14)$ revealed that participants were generally satisfied with the dietary intervention. Eighty-six percent reported that they were likely to continue following the diet after study completion with the remaining $14 \%$ stating they would likely continue with a modified version of the diet. Example quotes from the themes of accessibility, acceptability and adherence are provided in Table 4 and Additional file 3.

\section{Participant characteristics}

The 28 enrolled participants were mostly women (82\%), mean age $66 \pm 8$ years, who were overweight (body mass index $30.6 \pm 4.6$ ) (Table 5). All participants were Caucasian and most had pre-existing comorbidities (85\%) and knee pain persisting for more than one year (67\%).

\section{Dietary Intake}

While overall energy and protein intake remained unchanged between baseline and week 9 (mean change $-69.0 \mathrm{kcal}$ [ $95 \% \mathrm{CI}-308.8$ to 170.7$]$ and $-8.1 \mathrm{~g}$ [ -20.9 to 4.8], respectively), significant reductions were observed in total carbohydrate ( $-64.8 \mathrm{~g}$ [ -104.9 to -24.7$]$ (Fig. 2) and carbohydrate as a percent of total energy consumed $(-13.3 \%$ [ -18.2 to -8.4$]$ ) (Additional file 4$)$. Total fat intake increased over the 9-week period (22.5 g [7.7 to 37.3]) (Fig. 2) while saturated fat as a percent of total fat intake decreased $(-5.7 \%,[-11.0$ to -0.5$])$, whereas MUFAs and PUFAs percentage intake increased $(4.3 \%$ [1.3 to 7.4$]$ ) and (1.4\% [ -1.7 to 4.5$]$ ), respectively (Additional file 4).

\section{Patient-reported outcomes}

The desired treatment effect for all KOOS subscales and $\mathrm{KOOS}_{4}$ (improvement $>8-10$ points) was contained within the 95\% CI (Table 6). The individual treatment 


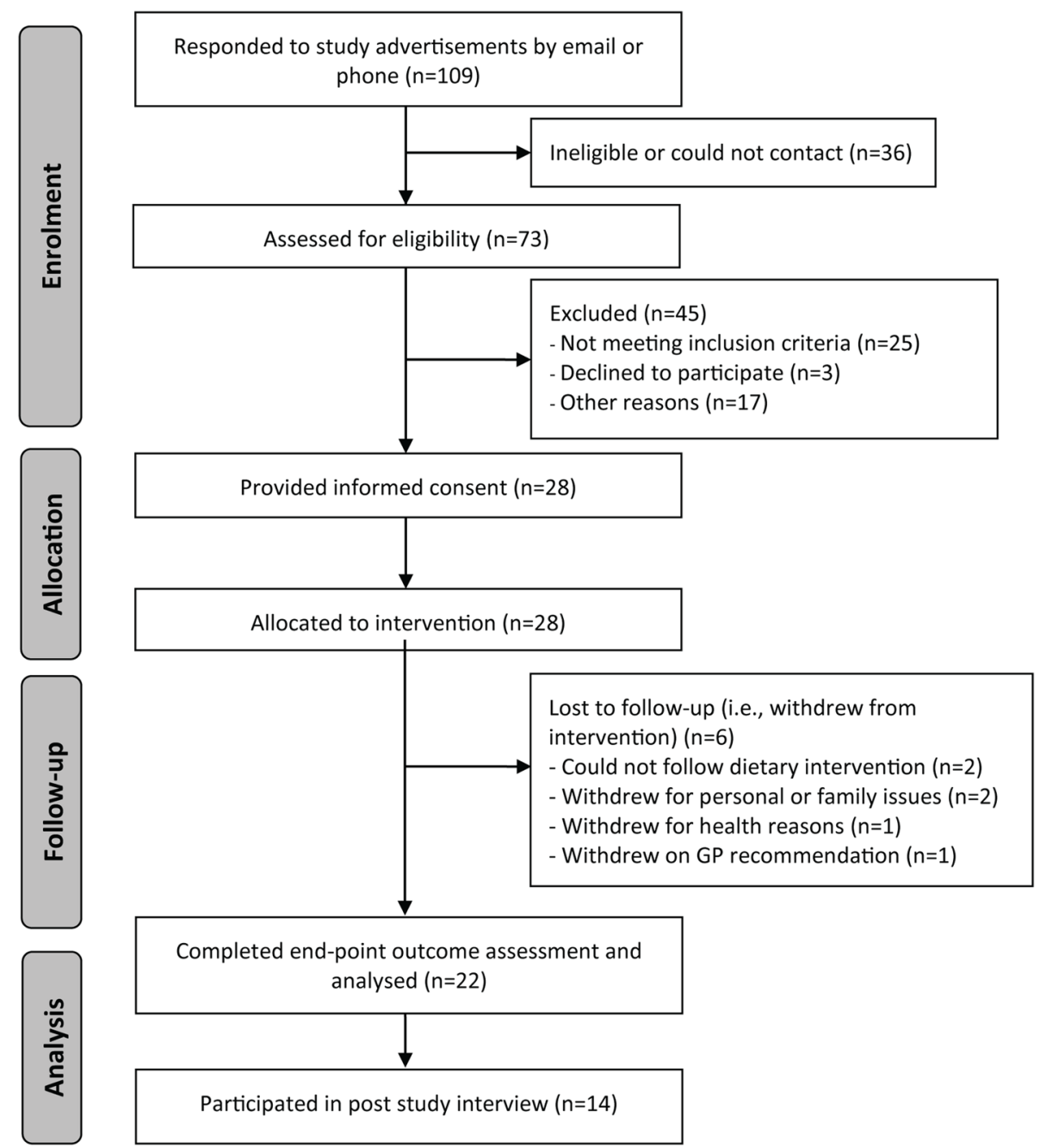

Fig. 1 Flow of participants through the study

responses for KOOS-QoL and proportion with improvements greater than the MDC appear in Fig. 3 (other subscales in Additional file 5). Health-related QoL also improved (EQ-5D health utility index mean 6.3, 95\% $\mathrm{CI}-0.44$ to 12.7$)$. On average, participants recorded a mean loss of body mass $(-3.0 \mathrm{~kg}, 95 \% \mathrm{CI}-3.6$ to -2.3$)$ and decreased BMI $\left(-1.0 \mathrm{~kg} / \mathrm{m}^{2}, 95 \% \mathrm{CI}-1.25\right.$ to -0.8$)$. Seven participants (32\%) reported using much less analgesic medication, $3(14 \%)$ less, 10 (46\%) the same amount, and $2(9 \%)$ more (one of whom had an acute flare of pain due to a fall).

\section{Discussion}

The results of this study suggest that a full-scale RCT designed to evaluate the effects of a telehealth delivered anti-inflammatory dietary intervention is feasible. Fiftyeight percent of eligible participants enrolled, attendance at scheduled appointments and adherence to the intervention was excellent, and most (86\%) participants were satisfied with the intervention expressing a desire to continue the diet beyond the study period. Additionally, worthwhile treatment effects were observed in participants completing the intervention for knee-related symptoms, function and QoL. The drop-out rate of $21 \%$ requires attention in the design of a full-scale RCT.

The significant interest to participate in this study by people with knee OA as evidenced by the high recruitment rates, together with the promising changes in important patient-reported outcomes, supports progression to a full-scale RCT. The rate of enrolment (58\%) was much higher than previously reported rates for other pilot RCTs recommending progression to a full-scale RCT (35\%) and was similar to other trials of dietary interventions [44]. Our recruitment rate of 14 per month was primarily drawn from individuals responding to a study advert in a newsletter sent out to all patients with knee 
Table 3 Feasibility outcomes

\begin{tabular}{|c|c|c|}
\hline & Anti-inflammatory intervention & Recommendations for full-scale clinical trial \\
\hline \multicolumn{3}{|l|}{ Recruitment and retention } \\
\hline Recruitment rate & 14 participants per month & $\begin{array}{l}\text { Could be increased utilising physiotherapy and orthopae- } \\
\text { dic clinics. }\end{array}$ \\
\hline Eligibility rate & 48 of $73(66 \%)$ screened participants eligible & \\
\hline Enrolment rate & 28 of $48(58 \%)$ of eligible participants enrolled & \\
\hline Drop-out rate & $6(21 \%)$ & $\begin{array}{l}\text { Strategies required to improve drop-out rate may include } \\
\text { better education of intervention and follow-up require- } \\
\text { ments prior to enrolment, having a patient ambassador or } \\
\text { using an interactive mobile app to optimise engagement. }\end{array}$ \\
\hline \multicolumn{3}{|l|}{ Adherence and attendance } \\
\hline Dietary adherence & $\begin{array}{l}96 \% \text { reported adherence on the Likert scale of } \geq 4 / 5 \text { at } \\
\text { final follow-up }\end{array}$ & $\begin{array}{l}\text { Increased meal plans/recipes. } \\
\text { Utilisation of interactive food recording tools. }\end{array}$ \\
\hline Telehealth attendance & $99 \%$ consult attendance & \\
\hline Food Diary completion & $100 \%$ completion of diaries & \\
\hline \multicolumn{3}{|l|}{ Adverse events } \\
\hline Injury or illness & $\begin{array}{l}N=2 \\
(1 \text { constipation, } 1 \text { increased knee pain following fall) }\end{array}$ & $\begin{array}{l}\text { Could incorporate more overt preventive strategies for } \\
\text { constipation. }\end{array}$ \\
\hline \multicolumn{3}{|l|}{ Acceptability of outcomes } \\
\hline Treatment satisfaction & $\begin{array}{l}\text { Participants reported appointments were appropriate } \\
\text { regarding: availability, frequency and duration. Partici- } \\
\text { pants were satisfied with the diet intervention with most } \\
\text { (86\%) of interviewed participants stating they would } \\
\text { continue the diet. }\end{array}$ & $\begin{array}{l}\text { Consider initial baseline face-to-face consultation with tele- } \\
\text { health follow-up. }\end{array}$ \\
\hline Time to collect data & $\begin{array}{l}\text { Baseline appointments completed in }<90 \mathrm{~min} \text {. Follow-up } \\
\text { appointments completed in } 10-15 \mathrm{~min} \text {. }\end{array}$ & \\
\hline $\begin{array}{l}\text { Completeness of patient- } \\
\text { reported outcomes }\end{array}$ & $\begin{array}{l}\text { Of the } 22 \text { participants attending the 9-week follow-up, } \\
\text { with a total of } 88 \text { data collection events ( } 4 \text { each): } \\
\text { - Missing data } n=1(1 \%) \\
\text { - Incomplete data } n=6(7 \%)\end{array}$ & Data checking mechanisms to reduce incomplete data. \\
\hline Adherence monitoring & $\begin{array}{l}15 \text { participants used Easy Diet Diary, } 7 \text { used paper food } \\
\text { records. Participants reported food diary was useful for } \\
\text { motivation and accountability. } \\
\text { Participants reported that the macronutrient tracker on } \\
\text { the Easy Diet Diary was helpful in providing real-time } \\
\text { analysis of foods consumed, which aided food choices. }\end{array}$ & \\
\hline
\end{tabular}

and hip OA in an existing registry $(\mathrm{n} \sim 2000)$ [45]. This rate suggests that a full-scale RCT of approximately 150 200 participants (estimated sample size to achieve $80 \%$ power based on a between-group difference of 10 points on the KOOS with a standard deviation of 15) $[39,46]$ could be recruited over a $12-18$ month period $[39,46]$. Avenues to increase the recruitment rate could include engaging with hospital, orthopaedic and physiotherapy clinics to directly notify existing patients of the study. This may be required with the addition of a control arm, which may mitigate the desire to participate. Alternative trial designs such as within-subject cross-over design could overcome this potential barrier to recruitment.

Telehealth delivery of the dietary intervention was supported by this feasibility study with excellent attendance at telehealth appointments (99\%) and remote completion of 3-day food diaries and other patient-reported outcomes (98\%). E-mail and text-message reminders, together with accessibility and flexibility of scheduling, helped to facilitate the high attendance and completion rates, with telehealth delivery considered acceptable and similarly effective to in-person delivery in the qualitative interview feedback. Eighty-six percent of participants interviewed stated they were satisfied with the dietary intervention and would continue following the diet beyond the study period. Two (9\%) participants reported adverse events - one related to constipation due to changed eating habits and the other an injury sustained unrelated to the diet. The risk of constipation was discussed in the initial education session as it is a known adverse outcome for diets higher in protein and fat, however, more overt preventive strategies may need to be implemented in future trials. One such strategy to implement would be encouraging the intake of dietary fibres, which were not increased from baseline during the feasibility study. This has the dual benefit of potentially 
Table 4 Supporting quotes from post-intervention interviews exploring the intervention accessibility, acceptability and adherence

Theme 1: Accessibility of telehealth appointments

Quote 1: I suppose the fact that you didn't have to travel to an appointment and find extra time to put into it was good.

Q2: It was good to have some flexibility if a time [for a telehealth appointment] didn't suit.

Q3: If possible in the future you have the [initial] face-to-face, do all that [baseline testing] and the rest of it would be just zoom.

Q4: Yep. That was good [flexible appointment scheduling with telehealth], because l'm a shift worker, so it was good to have some flexibility if a time didn't suit.

Q5: It [follow up appointments] didn't need to be face-to-face and lucky for that because we didn't have any face-to-face opportunities [due to COVID19 restrictions]. But still, like with using Zoom and all that, it's nearly like sitting in the same room anyhow.

Q6: Once I got my head around the Zoom, sort of sorted that out, in my brain, it was fine. I've got no issue with it [using telehealth instead of face-toface].

Theme 2: Acceptability of the dietary intervention

Q7: Actually, throughout the diet I found that, when I adhered to it [anti-inflammatory diet], I was far less likely to eat between meals, which was good. Q8: Yes. I'm going to continue the diet because I felt better.

Q9: Yeah, I will [continue the diet]. Because, clearly my pain levels have diminished and, yeah, I'm not a big carbohydrate eater anyway, so if I don't have those foods, it won't bother me.

Q10: Yeah. Generally, I really enjoyed it [the dietary intervention]

Q11:..After two or three weeks, it was quite enjoyable and the recipes that you provided and everything were really nice. So, that makes it easier, to have something tasty

Q12:... I would recommend it to anybody who has got the problems [osteoarthritis] that I have got.

Theme 3: Adherence to the dietary intervention

Q13: I think everyday / adhered to it.

Q14: Perfect ... I was perfect [adhering to diet]. I didn't do anything naughty at all.

Q15: I suppose, when I was having positive results out of it, when my knee was not hurting as much, when I could actually see that the swelling on my knee.. was going down, plus seeing the weight loss and everything. So, it wasn't hard to adhere to it.

Q16: I was really pleased we were in lockdown, I must admit. I think that would have been much more difficult to maintain [adherence to diet] going in and out of work everyday.

Theme 4: Comparison to exercise-intervention

Q17: Oh, the diet was easier to follow [compared to exercise intervention]. The diet was much easier to follow.

Q18: It was easier to follow the eating plan. Because I did GLA:D [exercise intervention] post a total knee replacement. So, that was hard for pain.

Q19: Oh, it [diet] was much easier because I find the exercises very tiring and hard.

Q20: I didn't really find the diet that hard to stick to. So, I would probably sort of say equal.

decreasing the adverse side effects of constipation and reducing the development of moderate and severe knee pain, which has been associated with low fibre intake [47, 48].

Participants reported being generally adherent to the anti-inflammatory diet, $27 \%$ were adherent everyday and $68 \%$ were adherent most of the time. This selfreported adherence data was supported by evidence of macronutrient consumption changes. Carbohydrate and refined grain intake significantly decreased, while dietary fats, mostly in the form of MUFAs and PUFAs, significantly increased. While average protein intake decreased by approximately eight grams, this was not statistically significant, and remained above $(>1.0 \mathrm{~g} / \mathrm{kg} /$ day) the recommended protein intake in older adults of $0.8 \mathrm{~g} / \mathrm{kg} / \mathrm{day}$ [48]. Participant feedback during qualitative interviews highlighted that the range of foods available ensured adequate satiety, with the provided example meal plans and recording of dietary intake aiding adherence. Furthermore, due to the experimental nature of the anti-inflammatory diet, more frequent and rigid nutrition counselling could be provided to future participants to ensure maintenance of restricted carbohydrate intake, particularly during longer intervention periods, with evidence that more carbohydrates were consumed the longer participants were enrolled (Fig. 2).

Participant retention is one aspect that requires attention in the design of a full-scale RCT. Strategies to improve a drop-out rate of $21 \%$ are needed, particularly as retention to longer-follow-ups may be more problematic. Although other trials have reported a similar dropout rate $(20 \%)$ for a dietary intervention, this was over a 6-month follow-up period [8]. Of the participants who withdrew, three were directly related to the study protocol and three were due to other personal matters unrelated to the diet. It is worth noting that the study was conducted in the middle of significant government-mandated COVID-19 restrictions in Australia, which may have contributed to a higher than usual drop-out rate. An initial face-to-face appointment prior to randomisation 
Table 5 Overview of baseline participant characteristics

\begin{tabular}{|c|c|}
\hline Variable & Total $(n=27)^{\#}$ \\
\hline Age, mean \pm standard deviation years & $66 \pm 8$ \\
\hline Female sex, n (\%) & $22(82)$ \\
\hline Height, mean \pm standard deviation $\mathrm{cm}^{\mathrm{a}}$ & $166.6 \pm 8.2$ \\
\hline Weight, mean \pm standard deviation $\mathrm{kg}^{\mathrm{a}}$ & $84.4 \pm 16.0$ \\
\hline Body mass index, mean \pm standard deviation $\mathrm{kg} \cdot \mathrm{m}^{-2 a}$ & $30.6 \pm 4.6$ \\
\hline Caucasian ethnicity, n (\%) & $27(100)$ \\
\hline \multicolumn{2}{|l|}{ Highest education level, n (\%) } \\
\hline Up to secondary school & $1(4)$ \\
\hline Completed secondary school & $8(30)$ \\
\hline Apprenticeship & $3(11)$ \\
\hline Bachelor's degree & $10(37)$ \\
\hline Post-graduate degree & $5(19)$ \\
\hline \multicolumn{2}{|l|}{ Employment, n (\%) } \\
\hline Full-time & $3(11)$ \\
\hline Part-time & $5(19)$ \\
\hline Casual & $1(4)$ \\
\hline Retired & $18(67)$ \\
\hline \multicolumn{2}{|l|}{ Living arrangement, $\mathrm{n}(\%)$} \\
\hline Alone & $5(19)$ \\
\hline With spouse & $18(67)$ \\
\hline With family & $4(15)$ \\
\hline \multicolumn{2}{|l|}{ Household income \$AUD, n (\%) } \\
\hline$<50,000$ & $13(48)$ \\
\hline$>50,000$ & $9(33)$ \\
\hline Undisclosed & $5(19)$ \\
\hline \multicolumn{2}{|l|}{ Co-morbidities, n (\%) } \\
\hline Diabetes & $1(4)$ \\
\hline Hypertension & $8(30)$ \\
\hline Dyslipidaemia & $5(19)$ \\
\hline Pulmonary disease & $1(4)$ \\
\hline Cancer & $3(11)$ \\
\hline Other ${ }^{c}$ & $5(19)$ \\
\hline \multicolumn{2}{|l|}{ Knee affected by osteoarthritis, n (\%) } \\
\hline Left & $14(52)$ \\
\hline Right & $11(41)$ \\
\hline Both & $2(7)$ \\
\hline Average knee pain (0-10), mean \pm standard deviation ${ }^{b}$ & $4.8 \pm 1.7$ \\
\hline Maximal knee pain (0-10), mean \pm standard deviation & $7.1 \pm 1.8$ \\
\hline \multicolumn{2}{|l|}{ Duration of knee pain, $n(\%)$} \\
\hline 0-6 months & $5(19)$ \\
\hline $6-12$ months & $4(15)$ \\
\hline $1-3$ years & $8(30)$ \\
\hline$>3$ years & $10(37)$ \\
\hline Past knee injury, n (\%) & $14(52)$ \\
\hline Family history of osteoarthritis, n (\%) & $18(67)$ \\
\hline Knee & $8(30)$ \\
\hline Other joint ${ }^{d}$ & $10(37)$ \\
\hline Analgesic use, $n(\%)^{b}$ & $22(82)$ \\
\hline Paracetamol & $16(59)$ \\
\hline
\end{tabular}

Table 5 (continued)

\begin{tabular}{ll}
\hline Variable & Total $(\boldsymbol{n}=\mathbf{2 7})^{\#}$ \\
\hline Oral NSAID & $6(22)$ \\
Topical NSAID & $3(11)$ \\
Glucosamine & $3(11)$ \\
Corticosteroid & $3(11)$ \\
Opioid & $1(4)$ \\
Codeine & $2(7)$ \\
Methotrexate & $1(4)$ \\
Anti-depressant (chronic pain) & $1(4)$ \\
\hline
\end{tabular}

NSAID Non-steroidal anti-inflammatory drug

\# One participant who withdrew from the study did not consent for their data to be included in the paper

a $n=3$ missing baseline anthropometry due to no equipment

${ }^{\mathrm{b}} n=1$ data incomplete: Participant did not complete knee pain or analgesic use

c Other medical conditions include coeliac disease, osteoporosis, vascular disease, fibromyalgia

d Other osteoarthritis includes: hip, hand, shoulder and back

may help to educate prospective participants and allow sufficient time to detail the study requirements and the importance of continued follow-up to minimise dropout. This may coincide well with collection of objective data (e.g., inflammatory markers, dual-energy $\mathrm{x}$-ray absorptiometry (DXA) body composition, functional performance) in a large-scale RCT, but would also increase travel/time requirements and potentially willingness to enrol.

The promising response in self-reported symptoms, function, QoL and weight loss over a relatively short 9-week intervention period, is consistent with the response to a similar 12-week low-carbohydrate diet $(<20 \mathrm{~g}$ first 3 weeks, then $<40 \mathrm{~g}$ thereafter $)$ in knee OA [25]. However, our study differed based on the dietary advice designed by our APD, which aimed to encourage anti-inflammatory foods and discouraged proinflammatory foods, rather than having a prescriptive carbohydrate target. Our approach was more feasible for participants and the diet was able to better promote nutrient intake (e.g Omega-3 fatty acids, MUFAs and PUFAs) that have evidence to improve OA symptoms [49]. Importantly, a worthwhile within-group effect (exceeding MDC) was contained within the 95\% CI for all KOOS subscales and $\mathrm{KOOS}_{4}$ after the 9-week intervention - a longer intervention period or combining the dietary intervention with exercise may enhance the treatment effect [8]. All participants had previously completed an OA specific exercise-therapy program (GLA:D) [45], yet despite this, were still experiencing ongoing pain. In qualitative interviews, participants expressed a desire to complete the diet and exercise interventions simultaneously to maximise outcomes. 


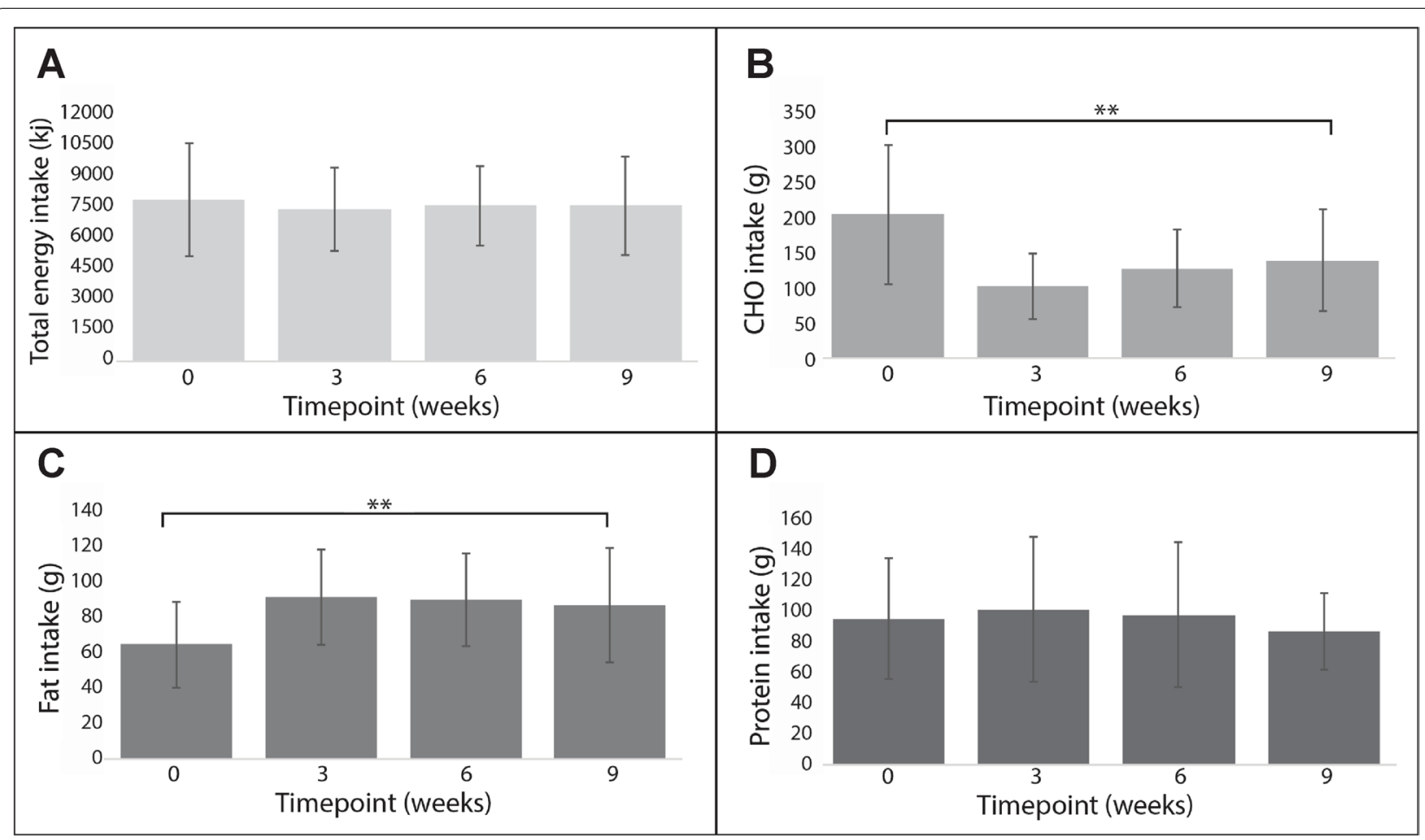

Fig. 2 Mean \pm standard deviation daily intake in those who completed all follow-ups ( $n=22)$. A) Total energy; B) Carbohydrate; C) Fat; D) Protein. ** Indicates significant absolute change in variable from baseline (week 0) to week 9

Table 6 Patient-reported and anthropometric data in participants who completed all follow-up $(n=22)$

\begin{tabular}{|c|c|c|c|c|c|c|c|}
\hline Outcome & Baseline & Week 3 & Week 6 & Week 9 & Change $^{\mathrm{a}}$ & $95 \% \mathrm{Cl}$ of change & MDC \\
\hline KOOS-Pain & $61.8 \pm 12.0^{b}$ & $63.1 \pm 11.4$ & $68.8 \pm 12.2^{c}$ & $68.4 \pm 12.3$ & $6.6 \pm 12.6$ & [0.9 to 12.4] & $8-10$ \\
\hline KOOS-Symptoms & $56.9 \pm 14.3^{b}$ & $57.3 \pm 15.4$ & $58.6 \pm 16.7^{c}$ & $62.5 \pm 17.7$ & $5.6 \pm 15.1$ & {$[-1.3$ to 12.5$]$} & $8-10$ \\
\hline KOOS-ADL & $68.2 \pm 15.9^{b}$ & $72.2 \pm 13.2^{b}$ & $75.8 \pm 14.6^{c}$ & $78.3 \pm 14.4$ & $10.1 \pm 14.3$ & [3.6 to 16.6$]$ & $8-10$ \\
\hline KOOS-Sport/Rec & $35.7 \pm 27.3^{b}$ & $47.4 \pm 27.9^{b}$ & $46.8 \pm 25.2^{c}$ & $46.9 \pm 29.6$ & $11.2 \pm 19.7$ & {$[2.2$ to 20.2$]$} & $8-10$ \\
\hline KOOS-QoL & $42.0 \pm 16.4^{b}$ & $46.3 \pm 14.6^{\mathrm{b}}$ & $50.9 \pm 14.5^{c}$ & $50.8 \pm 13.7$ & $8.8 \pm 14.7$ & [2.1 to 15.5$]$ & $8-10$ \\
\hline $\mathrm{KOOS}_{4}$ & $57.2 \pm 10.9^{b}$ & $59.95 \pm 10.7^{b}$ & $63.5 \pm 10.8^{c}$ & $65.0 \pm 12.4$ & $7.8 \pm 11.5$ & [2.5 to 13.0$]$ & $8-10$ \\
\hline EQ 5 D Utility & $0.70 \pm 0.16^{b}$ & $0.74 \pm 0.1$ & $0.74 \pm 0.11^{c}$ & $0.75 \pm 0.12$ & $0.04 \pm 0.16$ & {$[-0.03$ to 0.11$]$} & N/A \\
\hline EQ 5 DVAS & $75.2 \pm 15.1^{b}$ & $77.5 \pm 15.1$ & $78.9 \pm 15.4^{c}$ & $81.6 \pm 14.6$ & $6.3 \pm 16.0$ & {$[-0.9$ to 13.6$]$} & N/A \\
\hline Average Pain (0-100 mm) & $52.6 \pm 22.7^{b}$ & $52.1 \pm 21.3^{b}$ & $41.6 \pm 23.0^{d}$ & $43.6 \pm 27.5^{c}$ & $-8.9 \pm 35.6$ & {$[-26.1$ to 8.2$]$} & N/A \\
\hline $\mathrm{BMI}, \mathrm{kg} / \mathrm{cm}^{2}$ & $30.7 \pm 4.8^{d}$ & $29.7 \pm 4.6^{b}$ & $29.5 \pm 4.6^{c}$ & $29.6 \pm 4.3^{b}$ & $-1.0 \pm 0.8$ & {$[-1.4$ to -0.7$]$} & N/A \\
\hline Weight, kg & $86.6 \pm 15.0^{d}$ & $83.7 \pm 13.9^{b}$ & $82.7 \pm 13.8^{c}$ & $83.6 \pm 13.7^{b}$ & $-3.0 \pm 2.3$ & {$[-4.1$ to -1.8$]$} & N/A \\
\hline
\end{tabular}

KOOS Knee injury and Osteoarthritis Outcome Score, ADL Activities of daily living, QoL Quality of life, EQ 5D EuroQoL-5D, BMI Body mass index, MDC Minimal detectable change, VAS Visual analogue scale, $\mathrm{CI}$ Confidence interval

${ }^{\text {a }}$ Change indicates absolute change from baseline to week 9 . All data presented as mean \pm standard deviation for participants completing the intervention and had baseline data. Minimal detectable change values drawn from previous estimations [43]

${ }^{\mathrm{b}} n=1$ missing data relative to number of participants in each timepoint column

${ }^{c} n=2$ missing data relative to number of participants in each timepoint column

${ }^{d} n=3$ missing data relative to number of participants in each timepoint column

Previous trials have demonstrated a benefit of combining diet and exercise compared to diet or exercise alone on weight loss in overweight adults with knee OA, but the diet was not anti-inflammatory in nature [8]. In the current study, participants lost an average of $3 \mathrm{~kg}$ over the 9-week intervention period, similar to weight loss on normocaloric anti-inflammatory diets such as the Mediterranean diet $[25,26]$. 


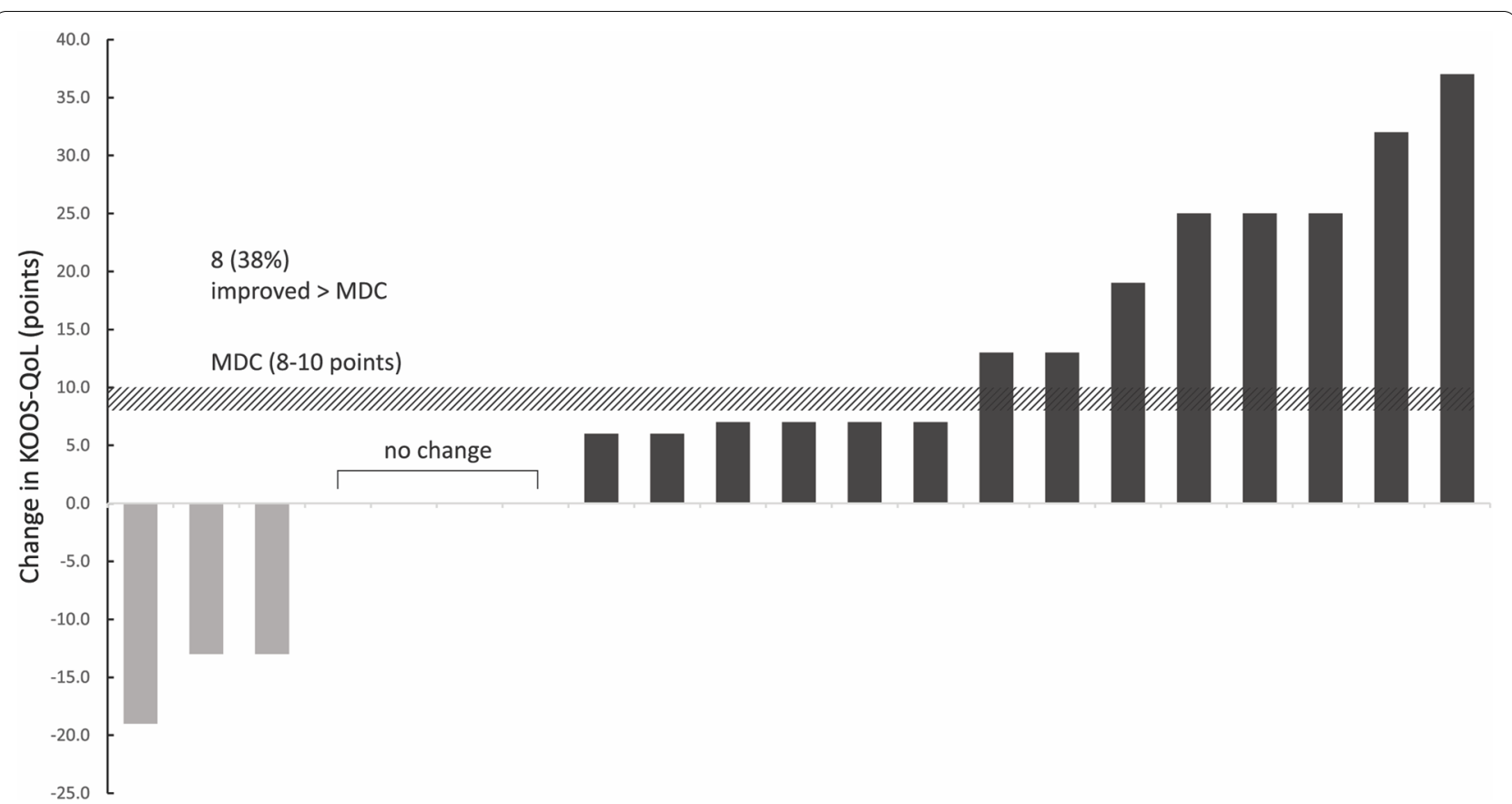

Fig. 3 Baseline to week 9 change scores per participant for the KOOS-QoL subscale. Baseline and follow-up KOOS scores range from 0 (extreme problems) to 100 (no problems). Positive change scores indicate an improvement in quality of life. KOOS, Knee injury and Osteoarthritis Outcome Score; MDC, minimal detectable change; QoL, quality of life

A limitation of the current study was that we did not determine acceptable thresholds of feasibility a priori; instead, we chose to explore these aspects to inform the design of future fully powered RCTs. Despite the promising outcomes reported by participants following the anti-inflammatory diet, it is important that the results are not interpreted as definitively supporting an anti-inflammatory diet for knee OA given the small sample size and lack of control group. We enrolled participants based on a symptomatic definition of knee OA and did not screen for joint structure (e.g., radiographic OA). However, clinical criteria for the diagnosis of knee OA does not rely on the presence of structural joint changes [50]. Further limitations of our study design include the lack of diversity in participants enrolled and the relatively short follow-up period, which limited our ability to determine long-erm sustainability. All participants had previously completed the GLA:D program and were motivated to improve their knee and general health, which may not accurately represent individuals with knee OA from the general population. Additionally, due to the inability to conduct face-to-face data collection during COVID-19 restrictions, our study relied on subjective data. Despite successfully pivoting the study in response to COVID19 restrictions, without blood samples to assess changes in inflammatory markers, it was not possible to confirm whether the improvement in symptoms was mediated by changes in systematic inflammation. We appreciate that the literature surrounding anti-inflammatory properties of foods and diets is often conflicting, and that further research is required to continue to objectively substantiate the anti-inflammatory nature of certain foods and low-inflammatory diets. We guided our anti-inflammatory intervention based on the existing literature of lowinflammatory or anti-inflammatory diets that have been shown to decrease systemic inflammation and improve health outcomes [21]. Future large-scale studies will be able to investigate drivers of symptomatic improvements in response to an anti-inflammatory diet. Other measures that would normally be assessed objectively (e.g., height, weight) were self-reported and we were unable to assess changes in body composition (waist-height ratio, DXA) and functional performance (e.g., sit to stand, walk tests).

\section{Conclusion}

A full-scale trial to evaluate the effectiveness of an antiinflammatory dietary intervention in knee $\mathrm{OA}$ is feasible. The likely worthwhile treatment effects and overwhelming positive feedback towards the telehealth delivered format highlights the potential for an anti-inflammatory diet intervention delivered by telehealth to effectively reduce pain, improve function and quality of life and result in weight loss. Additional strategies to minimise drop-out rates are required. 


\section{Abbreviations}

OA: Osteoarthritis; GLA:D: Good life with osteoarthritis from Denmark; KOOS: Knee injury and Osteoarthritis Outcome Score; ADL: Activities of daily living; QoL: Quality of life; RCT: Randomised control trial; EQ 5 D: EuroQol-5D; CHO: Carbohydrate; TEl: Total energy intake; MUFA: Mono-unsaturated fatty acids; PUFA: Poly-unsaturated fatty acids; MDC: Minimal detectable change.

\section{Supplementary Information}

The online version contains supplementary material available at https://doi. org/10.1186/s12891-022-05003-7.

Additional file 1. Anti-inflammatory diet information.

Additional file 2. Post-study interview questions and lines of enquiry.

Additional file 3. Major themes from post-study interview.

Additional file 4. Nutrient and Food Group intake in participants who completed all follow-ups.

Additional file 5. Change in Knee injury and Osteoarthritis Outcome Score (KOOS) subscale scores.

\section{Acknowledgements}

We would like to thank GLA:D Australia for assistance with participant recruitment. We would also like to acknowledge the participants for the generosity of their time.

\section{Authors' contributions}

All authors contributed to the conception and design of the study. IC, MF, BD, $A R$ and $A C$ contributed to participant recruitment, acquisition of data and intervention delivery. IC, MF and AC analysed the data. All authors contributed to the interpretation of data and drafted the manuscript, revised it critically for important intellectual content and gave final approval of the version to be published. All authors read and approved the final manuscript.

\section{Funding}

This trial was funded by a La Trobe University Sport, Exercise and Rehabilitation Research Focus Area (RFA) grant. The sponsors were not involved in the design and conduct of this study, in the analysis and interpretation of the data, and in the preparation, review, or approval of the manuscript.

\section{Availability of data and materials}

The datasets for the study are available from the corresponding author upon reasonable request.

\section{Declarations}

\section{Ethics approval and consent to participate}

The La Trobe University Human Research Ethics Committee approved the study (HEC19525). All study participants provided written informed consent.

\section{Consent for publication}

Not applicable.

\section{Competing interests}

PB is author of the book'A Fat Lot of Good', Penguin Random House Australia, 2018. All other authors declare that they have no competing interests.

\section{Author details}

${ }^{1}$ Melbourne Medical School, University of Melbourne, Parkville, Australia. ${ }^{2}$ La Trobe Sport and Exercise Medicine Research Centre, School of Allied Health, Human Services and Sport, La Trobe University, Bundoora, Victoria 3086, Australia. ${ }^{3}$ Department of Dietetics, Nutrition and Sport, La Trobe University, Melbourne, Australia.

Received: 29 September 2021 Accepted: 23 December 2021 Published online: 13 January 2022
References

1. Cross M, Smith E, Hoy D, Nolte S, Ackerman IN, Fransen M, et al. The global burden of hip and knee osteoarthritis: estimates from the global burden of disease 2010 study. Ann Rheum Dis. 2014;73(7):1323-30.

2. Australia Arthritis. Time to move: Osteoarthritis. A national strategy to remove a costly burden 2014 [Available from: http://www.arthritisaustra lia.com.au/images/stories/documents/Time\%20to\%20move/Final_Time to_Move_Osteoarthritis.pdf.

3. Ackerman IN, Osborne RH. Obesity and increased burden of hip and knee joint disease in Australia: results from a national survey. BMC Musculoskelet Disord. 2012;13:254.

4. Beswick AD, Wylde V, Gooberman-Hill R, Blom A, Dieppe P. What proportion of patients report long-term pain after total hip or knee replacement for osteoarthritis? A systematic review of prospective studies in unselected patients. BMJ Open. 2012;2(1):e000435.

5. Dowsey MM, Smith AJ, Choong PFM. Latent Class Growth Analysis predicts long term pain and function trajectories in total knee arthroplasty: a study of 689 patients. Osteoarthr Cartil. 2015;23(12):2141-9.

6. Nelson AE, Allen KD, Golightly YM, Goode AP, Jordan JM. A systematic review of recommendations and guidelines for the management of osteoarthritis: The chronic osteoarthritis management initiative of the U.S. bone and joint initiative. Semin Arthritis Rheum. 2014;43(6):701-12.

7. Uthman OA, van der Windt DA, Jordan JL, Dziedzic KS, Healey EL, Peat GM, et al. Exercise for lower limb osteoarthritis: systematic review incorporating trial sequential analysis and network meta-analysis. BMJ. 2013;347:f5555.

8. Messier SP, Mihalko SL, Legault C, Miller GD, Nicklas BJ, DeVita P, et al. Effects of intensive diet and exercise on knee joint loads, inflammation, and clinical outcomes among overweight and obese adults with knee osteoarthritis: the IDEA randomized clinical trial. JAMA. 2013:310(12):1263-73.

9. Christensen R, Bartels EM, Astrup A, Bliddal H. Effect of weight reduction in obese patients diagnosed with knee osteoarthritis: a systematic review and meta-analysis. Ann Rheum Dis. 2007;66(4):433-9.

10. Messier SP, Loeser RF, Miller GD, Morgan TM, Rejeski WJ, Sevick MA, et al. Exercise and dietary weight loss in overweight and obese older adults with knee osteoarthritis: the Arthritis, Diet, and Activity Promotion Trial. Arthritis Rheumatol. 2004:50(5):1501-10.

11. Messier SP, Beavers DP, Mihalko SL, Miller GD, Lyles MF, Hunter DJ, et al. The effects of intensive dietary weight loss and exercise on gait in overweight and obese adults with knee osteoarthritis. The Intensive Diet and Exercise for Arthritis (IDEA) trial. J Biomech. 2020:98:109477.

12. Hall KD, Kahan S. Maintenance of lost weight and long-term management of obesity. Med Clin N Am. 2018;102(1):183-97.

13. Anderson JW, Konz EC, Frederich RC, Wood CL. Long-term weightloss maintenance: a meta-analysis of US studies. Am J Clin Nutr. 2001;74(5):579-84

14. Griffin TM, Guilak F. The role of mechanical loading in the onset and progression of osteoarthritis. Exerc Sport Sci Rev. 2005;33(4):195-200.

15. van Spil WE, Jansen NW, Bijlsma JW, Reijman M, DeGroot J, Welsing PM, et al. Clusters within a wide spectrum of biochemical markers for osteoarthritis: data from CHECK, a large cohort of individuals with very early symptomatic osteoarthritis. Osteoarthr Cartil. 2012;20(7):745-54.

16. June RK, Liu-Bryan R, Long F, Griffin TM. Emerging role of metabolic signaling in synovial joint remodeling and osteoarthritis. J Orthop Res. 2016;34(12):2048-58

17. Galbete C, Kroger J, Jannasch F, lqbal K, Schwingshackl L, Schwedhelm C, et al. Nordic diet, Mediterranean diet, and the risk of chronic diseases: the EPIC-Potsdam study. BMC Med. 2018;16(1):99.

18. Babio N, Bullo M, Basora J, Martinez-Gonzalez MA, Fernandez-Ballart J, Marquez-Sandoval F, et al. Adherence to the Mediterranean diet and risk of metabolic syndrome and its components. Nutr Metab Cardiovasc Dis. 2009; 19(8):563-70.

19. Simopoulos AP. The importance of the ratio of omega-6/omega-3 essential fatty acids. Biomed Pharmacother. 2002;56(8):365-79.

20. Ansari MY, Ahmad N, Haqqi TM. Oxidative stress and inflammation in osteoarthritis pathogenesis: Role of polyphenols. Biomed Pharmacother. 2020;129:110452

21. Ricker MA, Haas WC. Anti-inflammatory diet in clinical practice: A review. Nutr Clin Pract. 2017;32:318-25. 
22. Russo GL. Dietary n-6 and n-3 polyunsaturated fatty acids: from biochemistry to clinical implications in cardiovascular prevention. Biochem Pharmacol. 2009;77(6):937-46.

23. Morales-Ivorra I, Romera-Baures M, Roman-Vinas B, Serra-Majem L. Osteoarthritis and the Mediterranean diet: A systematic review. Nutrients. 2018;10(8):07.

24. Richard C, Couture P, Desroches S, Lamarche B. Effect of the Mediterranean diet with and without weight loss on markers of inflammation in men with metabolic syndrome. Obesity. 2013:21(1):51-7.

25. Strath $L$, Jones CD, Philip George A, Lukens SL, Morrison SA, Soleymani T, et al. The Effect of Low-Carbohydrate and Low-Fat Diets on Pain in Individuals with Knee Osteoarthritis. Pain Med. 2020;21(1):150-60.

26. Dyer J, Davison G, Marcora SM, Mauger AR. Effect of a mediterranean type diet on inflammatory and cartilage degradation biomarkers in patients with osteoarthritis. J Nutr Health Aging. 2017;21(5):562-6.

27. Kelly JT, Reidlinger DP, Hoffmann TC, Campbell KL. Telehealth methods to deliver dietary interventions in adults with chronic disease: a systematic review and meta-analysis. Am J Clin Nutr. 2016;104(6):1693-702.

28. O'Brien KM, Hodder RK, Wiggers J, Williams A, Campbell E, Wolfenden $L$, et al. Effectiveness of telephone-based interventions for managing osteoarthritis and spinal pain: a systematic review and meta-analysis. PeerJ. 2018;6:e5846.

29. Eldridge SM, Chan CL, Campbell MJ, Bond CM, Hopewell S, Thabane $L$, et al. CONSORT 2010 statement: extension to randomised pilot and feasibility trials. BMJ. 2016;355:15239.

30. Kemp JL, Coburn SL, Jones DM, Crossley KM. The physiotherapy for femoroacetabular impingement rehabilitation study (physioFIRST): A pilot randomized controlled trial. J Orthop Sports Phys Ther. 2018;48(4):307-15.

31. Patterson BE, Barton CJ, Culvenor AG, Cooper RL, Crossley KM. Exercisetherapy and education for individuals one year after anterior cruciate ligament reconstruction: a pilot randomised controlled trial. BMC Musculoskelet Disord. 2021;22(1):64.

32. Tan JM, Menz HB, Crossley KM, Munteanu SE, Hart HF, Middleton KJ, et al. The efficacy of foot orthoses in individuals with patellofemoral osteoarthritis: a randomised feasibility trial. Pilot Feasibility Stud. 2019;5:90.

33. Barton CJ, Kemp JL, Roos EM, Skou ST, Dundules K, Pazzinatto MF, et al. Program evaluation of GLA:D ${ }^{\circledR}$ Australia: Physiotherapist training outcomes and effectiveness of implementation for people with knee osteoarthritis. Osteoarthritis Cartilage Open. 2021;3:100175.

34. Hoffmann TC, Glasziou PP, Boutron I, Milne R, Perera R, Moher D, et al. Better reporting of interventions: template for intervention description and replication (TIDieR) checklist and guide. BMJ. 2014;348:g1687.

35. Conway JM, Ingwersen LA, Moshfegh AJ. Accuracy of dietary recall using the USDA five-step multiple-pass method in men: an observational validation study. J Am Dietician Assoc. 2004;104(4):595-603.

36. Lancaster GA, Dodd S, Williamson PR. Design and analysis of pilot studies: recommendations for good practice. J Eval Clin Pract. 2004;10(2):307-12.

37. Braun V, Clarke V. Using thematic analysis in psychology. Qual Res Psychol. 2006;3(2):77-101.

38. Roos EM, Lohmander LS. The Knee injury and Osteoarthritis Outcome Score (KOOS): from joint injury to osteoarthritis. Health Qual Life Outcomes. 2003;1:64

39. Skou ST, Roos EM, Laursen MB, Rathleff MS, Arendt-Nielsen L, Simonsen $\mathrm{OH}$, et al. A randomized, controlled trial of total knee replacement. $\mathrm{N}$ Engl J Med. 2015;373:1597-606.

40. Roos EM, Roos HP, Lohmander LS, Ekdahl C, Beynnon BD. Knee Injury and Osteoarthritis Outcome Score (KOOS)--development of a self-administered outcome measure. J Orthop Sports Phys Ther. 1998;28(2):88-96.

41. Rabin R, de Charro F. EQ-5D: a measure of health status from the EuroQol Group. Ann Med. 2001;33(5):337-43.

42. Conner-Spady BL, Marshall DA, Bohm E, Dunbar MJ, Loucks L, Al Khudairy A, et al. Reliability and validity of the EQ-5D-5L compared to the EQ$5 \mathrm{D}-3 \mathrm{~L}$ in patients with osteoarthritis referred for hip and knee replacement. Qual Life Res. 2015;24(7):1775-84.

43. Naylor JM, Hayen A, Davidson E, Hackett D, Harris IA, Kamalasena G, et al. Minimal detectable change for mobility and patient-reported tools in people with osteoarthritis awaiting arthroplasty. BMC Musculoskelet Disord. 2014:15:235

44. Di Noia J, Schultz S, Monica D. Recruitment and retention of WIC participants in a longitudinal dietary intervention trial. Contemp Clin Trials Commun. 2019;16:100438.
45. Barton CJ, Kemp JL, Skou ST, Dundules K, Pazzinatto MF, Matthew F, et al. Prgaram evaluation of GLA:D Australia physiotherapist and patient outcomes. Osteoarthritis Cartilage. 2021;29:S402-3.

46. Frobell R, Roos E, Roos H, Ranstam J, Lohmander S. A randomized trial of treatment for acute anterior cruciate ligament tears. N Engl J Med. 2010;363:331-42

47. Dai Z, Lu N, Niu J, Felson DT, Zhang Y. Dietary fibre intake in relation to knee pain trajectory. Arthritis Care Res. 2017;69:1331-9.

48. Baum JL, Kim IY, Wolfe RR. Protein consumption and the elderly: what is the optimal level of intake? Nutrients. 2016;8:359.

49. Lu B, Driban JB, Xu C, Lapane KL, McAlindon TE, Eaton CB. Dietary fat intake and radiographic progression of knee osteoarthritis: Data from the Osteoarthritis Initiative. Arthritis Care Res. 2017;69(3):368-75.

50. Hochberg MC, Altman RD, Brandt KD, Clark BM, Dieppe PA, Griffin MR, et al. Guidelines for the medical management of osteoarthritis. Part I. Osteoarthritis of the hip. American College of Rheumatology. Arthritis Rheumatol. 1995;38(11):1535-40.

\section{Publisher's Note}

Springer Nature remains neutral with regard to jurisdictional claims in published maps and institutional affiliations.
Ready to submit your research? Choose BMC and benefit from:

- fast, convenient online submission

- thorough peer review by experienced researchers in your field

- rapid publication on acceptance

- support for research data, including large and complex data types

- gold Open Access which fosters wider collaboration and increased citations

- maximum visibility for your research: over $100 \mathrm{M}$ website views per year

At BMC, research is always in progress.

Learn more biomedcentral.com/submissions 